\title{
Cost effectiveness and cost utility of the noncoding blood glucose meter CONTOUR ${ }^{\circledR}$ TS
}

This article was published in the following Dove Press journal:

Diabetes, Metabolic Syndrome and Obesity:Targets and Therapy 10 February 2011

Number of times this article has been viewed

\author{
Przemyslaw Holko \\ Pawal Kawalec \\ HTA Centre, Kraków, Poland
}

Correspondence: Pawal Kawalec Centrum HTA, UI. Nuszkiewicza 13/19, 3 | -422 Kraków, Poland

$\mathrm{Tel}+48607345792$

Fax +48 I2 42I 7447

Email ppkawa@poczta.onet.pl
Aims: This study assessed the cost efficacy and cost utility of the automatic blood glucose meter CONTOUR ${ }^{\circledR}$ TS from the public payer (National Health Fund [NHF]) and payer (patient and NHF) perspectives over a 26-year analysis horizon.

Methods: Clinical effectiveness data were obtained from prior clinical studies of automatic versus manually coded blood glucose meters. Cost data were obtained from the NHF. The probability of procedure use related to diabetic complications was obtained from four medical centers in Poland. The incremental cost-effectiveness ratio related to 1 life year gained and the incremental cost-utility ratio related to 1 quality-adjusted life year gained were calculated.

Results: Assuming co-funding from public funds, introduction of the CONTOUR ${ }^{\circledR}$ TS is associated with savings of Polish złoty (PLN) 31,846.19 (€8916.93) and PLN 113,018.19 $(€ 31,645.09)$ per life year gained from the payer and public payer perspectives, respectively. Cost utility analyses showed that the CONTOUR ${ }^{\circledR}$ TS is associated with savings of PLN 40,465.59 $(€ 11,330.37)$ and PLN 11,434.82 (€3201.75) per quality-adjusted life year gained from the payer and the public payer perspectives, respectively.

Conclusion: The CONTOUR ${ }^{\circledR}$ TS appears superior to manually coded meters available in Poland both from the payer and the public payer perspectives and may represent an improved strategy for glycemic control.

Keywords: blood glucose self monitoring, costs and cost analysis, health care costs, diabetes mellitus, diabetes complications

\section{Introduction}

The worldwide prevalence of diabetes is increasing exponentially. In 1997, a reported 120 million people were affected by diabetes, and by 2010, that number rose to approximately 285 million. ${ }^{1,2}$ In Poland alone, the prevalence rate of diabetes is $9.3 \%$, or 2.7 million people. ${ }^{2}$ Patients with diabetes have an increased risk for cardiovascular disease, stroke, kidney dysfunction, and eye disease, among other complications. ${ }^{1}$ The risk of developing diabetic complications has been correlated with poor glycemic control. Glycemic variability, assessed by changes in glycosylated hemoglobin levels $\left(\mathrm{HbA}_{1 \mathrm{C}}\right)$, was shown to predict the development of microvascular complications in patients with diabetes. ${ }^{3}$ For this reason, diabetes management schemes are primarily focused on normalizing blood glucose levels by intensive glucose-lowering therapy.

Intensive glucose-lowering therapy involving administration of insulin by daily injections or an external insulin pump using frequent blood glucose monitoring to guide insulin therapy was shown to reduce the risk for developing retinopathy by as much as $76 \% .{ }^{4}$ Improved glycemic control reduces the risk of acute and chronic complications 
and is associated with an improvement in overall patient health. ${ }^{5,6}$ Additionally, improved glycemic control has been associated with a reduction in use of health care services and hospital admissions related to diabetic complications, resulting in lower medical costs for patients with diabetes. ${ }^{7,8}$ Successful glucose-lowering therapy depends on correct measurement of blood glucose levels using blood glucose meters. Incorrect measurements can lead to incorrect insulin dosing, which could result in a severe hypoglycemic event requiring hospitalization or inappropriate control of glycemic levels.

The use of manually coded blood glucose meters is associated with a higher incidence of incorrect measurements and concomitant administration of inappropriate insulin doses compared with automatic blood glucose meters. ${ }^{9}$ In one clinical study ${ }^{10}$ of 193 patients with diabetes, $16 \%$ of patients using manually calibrated blood glucose meters miscoded them, resulting in significant errors in blood glucose measurements. Additionally, $17 \%$ of patients using manually coded blood glucose meters considered coding to be difficult, even after instruction. Alternately, $99 \%$ of patients using automatic blood glucose meters considered the use of the systems to be relatively simple. ${ }^{10}$

The CONTOUR ${ }^{\circledR}$ TS system, an automatic blood glucose meter, is the only blood glucose monitoring system available in the Polish market that is equipped with No Coding ${ }^{\text {TM }}$ technology and that corrects blood glucose levels for the hematocrit effect. However, among the more than 10 meters available, only manually coded glucose meters are co-funded by the National Health Fund, some of which do not correct for the hematocrit effect. The improved efficacy of the CONTOUR ${ }^{\circledR}$ TS system for intensive glucose-lowering therapy compared with manually coded systems has been shown in three clinical studies. ${ }^{9-11}$ The purpose of the current study is to evaluate the effects of replacing manually coded blood glucose meters with the CONTOUR ${ }^{\circledR}$ TS system in diabetes management schemes on the cost of patient care within an analysis horizon of 26 years using data from 2006-2007. The cost effectiveness and cost utility of the CONTOUR ${ }^{\circledR}$ TS system, which is assumed to be co-funded by the National Health Fund (NHF) as a reimbursed medical device, will be evaluated from the perspective of the public payer (NHF) and the payer (patient and NHF) as compared with manually coded blood glucose meters available in Poland. These analyses will take into account the relative cost of daily glucose monitoring and the effect of the analyzed meters on clinically relevant diabetic complications, which will be used to determine the number of life years and quality-adjusted life years gained by use of the CONTOUR ${ }^{\circledR}$ TS system.

\section{Research design and methods Clinical effectiveness analysis}

A systematic review of the literature was conducted, and three clinical studies ${ }^{9-11}$ were identified that evaluated the efficacy of automatic blood glucose meters compared with manual blood glucose meters. The data from these three clinical studies were used in evaluating the effects of automatic versus manually coded blood glucose meters on life years gained and quality-adjusted life years. Two automatic blood glucose meters and three manually coded glucose meters were evaluated for the correlated risk of administering incorrect insulin dosages in the study by Raine and colleagues. ${ }^{9}$ These results were used in the Monte Carlo analysis to develop predictions of erroneous insulin administration associated with the use of an automatic glucose meter, incorrectly coded manual glucose meter, and correctly coded manual glucose meter. The effect of certain diabetic complications on patients' quality of life was determined in the study by Frank and colleagues, ${ }^{11}$ and these data were used for evaluating the quality of life for patients with diabetes. The age-dependent quality of life of the general population versus diabetic patients, reported in the Cost Effectiveness Analysis Registry Database at the Center for the Evaluation of Value and Risk in Health, ${ }^{12}$ was also used in quality of life analyses. The determined effects of hematocrit on the validity of blood glucose measurements using the CONTOUR ${ }^{\circledR}$ TS system were used in efficacy evaluations. ${ }^{11}$

\section{Cost analysis}

Costs were analyzed separately from the perspective of the public payer (NHF) and the payer (NHF and patient). The cost of hospital procedures, medication, outpatient visits, and rehabilitation were obtained from the following sources developed by the NHF: the "List of active substances used in therapeutic (drug) schemes"; the "Catalogue of hospital services" (Appendix No. 2 to Ordinance No. 40/2007 of the President of the NHF of June 26, 2007); the "Catalogue of Outpatient Services of the National Health Fund" (Appendix No. 1 to Ordinance No. 14/2007 of the President of the NHF of March 29, 2007); and the "Catalogue of Therapeutic (Drug) Schemes" (Ordinance No. 11/2007 of the President of the NHF of March 16, 2007 and Ordinance No. 80/2006 of September 18, 2006). Per patient costs of reimbursement and medication for diabetes and related complications were obtained from the Ministry of Health Web site, ${ }^{13}$ and additional product cost data were obtained from the Medycyna Praktyczna portal. ${ }^{14}$ The cost of using 
the CONTOUR ${ }^{\circledR}$ TS blood glucose meter was determined using information from Bayer. It was assumed, based on clinical experience, that each patient in the analyzed population measured blood glucose levels once daily using the CONTOUR ${ }^{\circledR}$ TS system or a manually coded glucose meter. The cost per test strip to the public payer and the payer were assessed separately using the assumed retail price of Polish złoty (PLN) 47.81 ( $€ 13.39)$ per package of test strips for the CONTOUR ${ }^{\circledR}$ TS meter and the mean cost of a package of test strips for manually coded blood glucose meters sold in Poland over a 13-month period, which was weighted by the number of packages sold. These values were then used in cost-effectiveness and cost utility analyses. It was assumed that the cost of using a blood glucose meter would be reimbursed $100 \%$ to a reimbursement limit of PLN 47.81 $(€ 13.39)$. PLN were converted to Euros $(€)$ at an exchange rate of PLN $1=€ 0.28$ (average rate in 2008).

Data on the percentage of patients undergoing medical procedures related to complications of diabetes, such as acute coronary syndrome, stroke, diabetic foot syndrome, diabetic retinopathy, nephropathy, and a serious hyperglycemic event requiring hospitalization, were obtained from four medical centers in Malopolska and from consultation with medical experts. The cost of therapy for the treatment of stable coronary disease following an episode of acute coronary syndrome was estimated based on the guidelines of the Polish Cardiac Society, consultation with cardiologists, and data from the Medycyna Praktyczna Web site. ${ }^{14}$ Since a 26-year time horizon was used in this analysis, costs and outcomes that were measured in a single year were discounted at a rate of 5\% per year, according to the Guidelines of the Health Technology Assessment Agency. ${ }^{15}$ The value of one point in settlements between service provider and public payer was assumed to be PLN 10.50 (€2.94) for hospital procedures, PLN 7.80 (€2.18) for outpatient treatment, and PLN 0.90 ( $€ 0.25$ ) for rehabilitation. The cost of pharmacotherapy for patients following acute myocardial infarction included clopidogrel for $50 \%$ of the patients within the first year or ticlopidine for the remaining patients, along with beta-blockers, statins, and angiotensinconverting enzyme inhibitors, which for the purposes of cost analysis were assumed to be carvedilol, simvastatin, and enalapril, respectively. For the cost of medication for acute coronary syndromes, it was assumed that the public payer would cover only the cost of abciximab therapy, at a cost of PLN 136.50 (€38.22) per $1 \mathrm{mg}$. Standard biostatistical and epidemiological methods were used in all cost analyses.

\section{Cost effectiveness and cost utility analyses}

Cost effectiveness was expressed as the incremental cost-effectiveness ratio (ICER) when manually coded blood glucose meters were replaced with the CONTOUR ${ }^{\circledR} \mathrm{TS}$ system in diabetes management schemes, which was calculated as the ratio of the additional cost incurred in relation to 1 life year gained resulting from use of the CONTOUR ${ }^{\circledR} \mathrm{TS}$ system. A threshold value of PLN 58,000 (€16,240), based on the annual cost of dialysis treatment, was assumed for cost effectiveness. Cost utility was expressed as the incremental cost-utility ratio (ICUR) when manually coded blood glucose meters were replaced with the CONTOUR ${ }^{\circledR}$ TS system in diabetes management schemes, which was calculated as the ratio of additional cost incurred by use of the CONTOUR ${ }^{\circledR}$ TS system in relation to 1 quality-adjusted life year. The threshold value for cost utility was calculated by correcting the threshold cost for 1 life year gained for the highest utility of the patients' health state and was determined to be PLN $76,000(€ 21,280)$. Both cost effectiveness and cost utility were calculated from the perspectives of the public payer and the payer, with an analysis horizon of 26 years.

\section{Modeling}

The Markov process was used to evaluate the cost effectiveness and clinical efficacy of the CONTOUR ${ }^{\circledR}$ TS system versus manually coded meters over a 26-year analysis horizon, and the values obtained were enhanced by the Monte Carlo method simulation. The starting point of this analysis was assumed to be the introduction of patients to intensive glucose-lowering therapy requiring the use of a blood glucose meter. The 26-year analysis horizon corresponds with the life expectancy of a patient with diabetes based on the average age (53 years) of patients with diabetes in Poland. ${ }^{16}$ In this analysis, the baseline size of the populations in the study (CONTOUR ${ }^{\circledR}$ TS system) and control (manually coded blood glucose meters available in Poland) groups was assumed to be equal. The model used in this study analyzed the fate of hypothetical patients in the study and control groups, based on the probabilities of specific clinical outcomes associated with each of the analyzed systems, which were determined from data collected from clinical efficacy studies and epidemiological studies.

Based on data from the probability of measurement errors using automatically and manually coded blood glucose meters from the previously mentioned clinical study, ${ }^{9}$ the Monte Carlo method as described by Raine and colleagues, ${ }^{9}$ 
with a uniform continuous distribution, was used to generate 2500 "real" blood glucose level values. A hematocrit value, within the range of $0 \%-100 \%$, was assigned to each "real" glucose concentration, and bias values were assigned to three different ranges of hematocrit values as follows: $0 \%-20 \%$ hematocrit had a bias level of $5.1 \%, 20 \%-70 \%$ had a bias of $5.8 \%$, and $70 \%-100 \%$ had a bias of $6.4 \%$. The CONTOUR ${ }^{\circledR}$ TS system was attributed a within-run coefficient of variation (CV) of $6.0 \%$. The CV, bias, and "real" blood glucose levels were used to calculate the glucose levels measured by the CONTOUR ${ }^{\circledR}$ TS system. The number of insulin units required by the patient was assigned to the "real" and measured blood glucose levels. The percentage of events in which insulin units were incorrectly assigned was calculated based on the CONTOUR ${ }^{\circledR}$ TS measurements, and this value was used to calculate percentages of patients with incorrect measurements using the CONTOUR ${ }^{\circledR}$ TS system or a manually coded blood glucose meter. According to clinical studies, approximately $16 \%$ of patients using manually coded blood glucose meters miscode them, ${ }^{10}$ and the probability of incorrect insulin dosing was calculated using this value. Using the ratio of percentage of measurements to probability, the percentage of measurement errors with the CONTOUR ${ }^{\circledR}$ TS system and the probabilities of errors for automatically and manually coded blood glucose meters were used to calculate the percentage of incorrect measurements associated with manually coded glucose meters, which allowed a direct comparison of the efficacy of the CONTOUR ${ }^{\circledR}$ TS system and manually coded blood glucose meters.

The change in blood glucose concentration weighted by the percentage of incorrect measurements was determined by assigning each measurement error a maximum difference in blood glucose concentration resulting from incorrect insulin dosing and assumed that 1 unit of insulin lowers glucose concentrations by $50 \mathrm{mg} / \mathrm{dL}$. The change in the level of glycosylated hemoglobin resulting from erroneous insulin dosage, which was used to predict transitions between clinical states, was calculated using the values proposed by Goldstein and colleagues, ${ }^{17}$ correlating blood glucose concentration with $\mathrm{HbA}_{1 \mathrm{C}}$ levels. The $\mathrm{HbA}_{1 \mathrm{C}}$ change was calculated for patients using the CONTOUR ${ }^{\circledR}$ TS system or manually coded blood glucose meters. The $\mathrm{HbA}_{1 \mathrm{C}}$ levels of patients using the CONTOUR ${ }^{\circledR}$ TS and those using manually coded blood glucose meters were calculated as the sum of the baseline $\mathrm{HbA}_{1 \mathrm{C}}$ value, $\mathrm{HbA}_{1 \mathrm{C}}$ change resulting from incorrect insulin dosing, and the value of $\mathrm{HbA}_{1 \mathrm{C}}$ lowering due to intensive monitoring of blood glucose levels, as reported by Farmer and colleagues. ${ }^{18} \mathrm{~A}$ value of $-0.17 \% \mathrm{HbA}_{1 \mathrm{C}}$ was assigned to the CONTOUR ${ }^{\circledR}$ TS system, and a value of $-0.14 \%$ was assigned to manually coded blood glucose meters, reflecting the higher precision associated with the CONTOUR ${ }^{\circledR} \mathrm{TS}$ system compared with manually coded meters. It is assumed that the patients with incorrectly measured blood glucose levels sought outpatient treatment twice as frequently as patients with correctly monitored glucose levels, increasing from one visit in 3 months to two visits in 3 months.

The Markov model is often used for simulating the clinical course and associated costs of chronic disease. The disease course is divided into clinical states, and the probabilities of transitions between states and the costs related to individual states are designated. The Markov model used in this analysis included the following states: "no events", which consisted of the substates "first year after acute coronary syndrome (ACS)", "subsequent years after ACS", "postamputation", "post-end stage renal disease", and "patients without diabetic complications"; "serious hypoglycemia"; "ACS"; "stroke"; "end stage renal disease"; "amputation"; "retinopathy"; and "death". The $\mathrm{HbA}_{1 \mathrm{C}}$ levels for the study and control groups were used to calculate the probabilities of transitions between states. Probabilities for transitions between states were calculated using the CORE model at the baseline point in analysis. ${ }^{19}$ In subsequent analysis cycles, the CORE model was used for the probabilities of serious hypoglycemic events, end-stage renal disease, amputation, re-amputation, retinopathy, or proliferative retinopathy, or the risk reduction of an event associated with a $1 \%$ reduction in $\mathrm{HbA}_{1 \mathrm{C}}$, as reported by Stratton and colleagues ${ }^{20}$ and Molyneaux and colleagues, ${ }^{21}$ was used for the probabilities of acute coronary syndrome, stroke, all-cause death, and cardiovascular death to more accurately evaluate the effect of CONTOUR ${ }^{\circledR}$ TS reimbursement for the payer and public payer. In the Markov model used in this study, patients' lives were divided into a series of 6-month cycles, and each patient could have only one health status and associated probability in a given cycle.

Each patient was assigned to the "no events" state, substate of "diabetics", for introduction into the model. In subsequent cycles, patients could remain in their current state or transition to other states; however, patients in the "stroke", "ACS", "end stage renal disease", "serious hypoglycemia", or "amputation" state could not remain in those states for more than one cycle. The results of a clinical study ${ }^{20}$ correlating the risk of ACS and stroke with $\mathrm{HbA}_{1 \mathrm{C}}$ level was used to estimate the number of patients with ACS or stroke. The probabilities of diabetes-related deaths were calculated based on the results of a study ${ }^{22}$ that determined the ratio of 
mortality increase for patients with diabetes versus healthy individuals. The probabilities of diabetes-related deaths were reduced by $21 \%$ per each $1 \%$ reduction in $\mathrm{HbA}_{1 \mathrm{C}}$ level as a result of intensive glucose-lowering therapy. There is no direct correlation between $\mathrm{HbA}_{1 \mathrm{C}}$ level and the probability of transition from the "proliferative retinopathy" to the "blindness" state, so a constant risk of vision loss event was assumed, and the 6-month probability was calculated as $0.96 \%$. The $\mathrm{HbA}_{1 \mathrm{C}}$ level-dependent probability of serious hypoglycemia requiring hospitalization was calculated as $0.462 \%$, with an annual hypoglycemia risk of $0.231 \%$.

Patients in the "No events" state were assigned to one of the following substates: "first year post-ACS," "subsequent years post-ACS," "post-amputation," "post-end stage renal disease," and "diabetics" (for patients without diabetic complications). The number of surviving patients in all states in the study (CONTOUR ${ }^{\circledR}$ TS) and control (manually coded blood glucose meters available in Poland) groups were discounted and summed after all analyzed periods. The difference in the sum of discounted 6-month periods of life between the study and control groups represented the cumulative 6-month periods of life gained as a result of replacing manually coded meters with the CONTOUR ${ }^{\circledR}$ TS system. This value was divided by 2 to give the value of life years gained attributable to CONTOUR ${ }^{\circledR}$ TS monitoring. The determined life years gained accumulated within the 26-year analysis horizon were divided through the cohort size (10,000 patients) to obtain life years gained per standard patient. To estimate quality-adjusted life years gained, the additional life cycles gained were multiplied by the value of quality of life of patients within a given cycle and then discounted. These quality-adjusted life cycles were summed, transformed into annual values, and calculated per patient. The difference between the quality-adjusted life years for one patient in the study group and quality-adjusted life years for one patient in the control group was used to determine the additional quality-adjusted life years resulting from inclusion of the CONTOUR ${ }^{\circledR}$ TS system in diabetes management schemes.

Due to the higher precision of glucose measurement, which translates into a lower $\mathrm{HbA}_{1 \mathrm{C}}$ level, patients in the study group will generate lower costs for therapy of diabetic complications relative to patients in the control group. For that reason, costs related to patients being a specific state of the Markov model were calculated separately for patients using the CONTOUR ${ }^{\circledR}$ TS system and patients using manually coded meters. The costs related to treatment of patients in a specific state for 1 cycle, including hospitalizations, pharmacotherapy, outpatient visits, and rehabilitation, were considered in cost analyses. In this model, the values of discounting rates were transformed into 6-month rates using the formula $m=1-(1-\mathrm{p})^{1 / 2}$, where $p$ is the annual rate and $m$ is the 6 -month rate. The value of $m$ was $2.53 \%$ for costs and effects. The Markov model was subject to internal validation, and the program code was analyzed for errors independently by two researchers.

\section{Sensitivity analyses}

Sensitivity analyses were performed to determine the effects of model variables, including age, glucose level, manually coded meter compared with CONTOUR ${ }^{\circledR}$ TS, discount rates for costs and effects, and price of test strips, on the cost-effectiveness and cost-utility results from the primary analysis. For sensitivity analysis, patients using both the CONTOUR $^{\circledR}$ TS system and manually coded meters were assigned the same $\mathrm{HbA}_{1 \mathrm{C}}$ reduction of $-0.17 \% \mathrm{HbA}_{1 \mathrm{C}}$, rather than the values of $-0.17 \% \mathrm{HbA}_{1 \mathrm{C}}$ and $-0.14 \%$, which were used in the primary analysis for the CONTOUR ${ }^{\circledR}$ TS system and manually coded meters, respectively. This exclusion was applied in the primary analysis to account for the higher level of diabetic control achieved by patients in the CONTOUR $^{\circledR}$ TS group. The effect of lowering or increasing the patients' age by 10 years relative to the age of 53 years, which was used in all primary analyses, was examined in the sensitivity analysis, and subpopulation analyses of the age groups 43-53 and 53-63 years were conducted. For sensitivity analysis, the measured outcomes for CONTOUR ${ }^{\circledR}$ TS system were compared with those determined for the ACCUCHEK $^{\circledR}$ Active System, the most commonly used blood glucose meter in Poland, rather than all manually coded blood glucose meters as in the primary analysis. Discount rates of $0 \%$ per year were assumed for both costs and effects for sensitivity analysis according to the Guidelines of the Health Technology Assessment Agency. For 2-way sensitivity analyses, the discount rate for costs was assumed to be $0 \%$ per year with a discount rate for effects of 5\% per year, and, conversely, a discount rate for costs was assumed to be $5 \%$ per year with a discount rate for effects of $0 \%$ per year. Since the price of a package of test strips for the CONTOUR ${ }^{\circledR} \mathrm{TS}$ system is variable, sensitivity analyses were conducted to calculate threshold prices at which the CONTOUR ${ }^{\circledR}$ TS system is superior to the compared manually coded glucose meters. Threshold prices were calculated for following conditions: the retail price of test strips for the CONTOUR ${ }^{\circledR}$ TS system does not affect the reimbursement limit; the reimbursement limit is based on the retail price of a package of test strips for the CONTOUR ${ }^{\circledR}$ TS system; test strip packages are 
reimbursed $100 \%$ by the NHF; and the compared test strip costs are for all test strips used in manually coded meters available in the Polish market and for test strips used in the ACCU-CHEK ${ }^{\circledR}$ active system.

\section{Results}

\section{Clinical effectiveness analysis}

Use of the CONTOUR ${ }^{\circledR}$ TS system was associated with significant $(P<0.0001$ for both) increase in life years gained $(0.0017$ [standard deviation $(\mathrm{SD})=0.0002])$ and quality-adjusted life years $(0.0046[\mathrm{SD}=0.0002])$ per patient in the 26-year analysis horizon compared with manually coded blood glucose meters; the extrapolated effect on $\mathrm{HbA}_{1 \mathrm{C}}$ levels was established to be a $0.09 \%$ difference. The CONTOUR ${ }^{\circledR}$ TS system was associated with a reduction in the incidence of certain diabetic complications, including vision loss, amputation due to diabetic foot syndrome, and serious hypoglycemic events requiring hospitalization, compared with manually coded blood glucose meters. However, a slight increase in the incidence of acute coronary syndrome events was noted among patients using the CONTOUR ${ }^{\circledR}$ TS system, likely resulting from the reduced mortality associated with use of this system.

\section{Cost analysis}

The following costs were identified as significant from the public payer and payer perspectives: cost of products used in the treatment of diabetes and its complications; cost of outpatient visits related to diabetes and its complications; cost of therapy for stroke or acute coronary syndrome, including hospitalizations, medical procedures, abciximab and other pharmacotherapy, and rehabilitation; cost of therapy for end-stage renal disease, including hemodialysis or kidney transplant; cost of retinopathy treatment, including hospitalization and vitrectomy; cost of hospitalization due to serious hypoglycemia; and cost of diabetic foot syndrome, including amputations. The costs of various clinical procedures associated with the treatment of these complications were assessed and are presented in Table 1. These costs, in addition to costs for pharmacotherapy and outpatient visits related to ACS, outpatient visits to a diabetes clinic (two visits in 6 months for patients with correctly measured blood glucose levels and four visits in 6 months for patients with incorrectly measured blood glucose levels), and the cost of daily blood glucose monitoring, assuming one strip used daily, were considered in determining the total cost of diabetes treatment per patient in the 26-year analysis horizon from the perspective of the public payer and the payer for the CONTOUR ${ }^{\circledR}$ TS system
Table I Costs associated with common interventions for select complications associated with diabetes

\begin{tabular}{|c|c|c|}
\hline \multirow[t]{2}{*}{ Treatment } & \multicolumn{2}{|c|}{ Total cost } \\
\hline & PLN & $€$ \\
\hline \multicolumn{3}{|l|}{ Acute coronary syndrome } \\
\hline $\begin{array}{l}\text { Hospitalization for invasive } \\
\text { treatment }\end{array}$ & 2200.00 & 616.00 \\
\hline $\begin{array}{l}\text { ACS without increased } \\
\text { myocardial markers }\end{array}$ & 1650.00 & 462.00 \\
\hline $\begin{array}{l}\text { Hospitalization in an } \\
\text { intensive cardiac care unit }\end{array}$ & 990.00 & 277.20 \\
\hline $\begin{array}{l}\text { Balloon coronoplasty } \\
\text { without stenting }\end{array}$ & 3850.00 & 1078.00 \\
\hline Coronoplasty with stenting & 8800.00 & 2464.00 \\
\hline $\begin{array}{l}\text { Introduction of intra-aortic } \\
\text { contrapulsation }\end{array}$ & 3960.00 & 1108.80 \\
\hline Endocavitary stimulation & 660.00 & 184.80 \\
\hline Cardiac rehabilitation & 2430.00 & 680.40 \\
\hline $\begin{array}{l}\text { Outpatient visit with primary } \\
\text { care physician }\end{array}$ & 57.00 & 15.96 \\
\hline $\begin{array}{l}\text { Type II outpatient visit with } \\
\text { cardiologist }\end{array}$ & 39.90 & 11.17 \\
\hline $\begin{array}{l}\text { Type III outpatient visit with } \\
\text { cardiologist }\end{array}$ & 69.83 & 19.55 \\
\hline \multicolumn{3}{|l|}{ Stroke } \\
\hline $\begin{array}{l}\text { Basic diagnostics and treatment } \\
\text { (up to } 3 \text { days) }\end{array}$ & 880.00 & 246.40 \\
\hline Extended diagnostics & 1650.00 & 462.00 \\
\hline $\begin{array}{l}\text { Basic diagnostics and treatment } \\
\text { (more than } 3 \text { days) }\end{array}$ & 1980.00 & 554.40 \\
\hline $\begin{array}{l}\text { Treatment in a stroke ward } \\
\text { (up to } 3 \text { days) }\end{array}$ & 1980.00 & 554.40 \\
\hline $\begin{array}{l}\text { Treatment in a stroke ward } \\
\text { (more than } 3 \text { days) }\end{array}$ & 6600.00 & 1848.00 \\
\hline $\begin{array}{l}\text { Type II outpatient visit with } \\
\text { neurologist }\end{array}$ & 133.00 & 37.24 \\
\hline $\begin{array}{l}\text { Type III outpatient visit with } \\
\text { neurologist }\end{array}$ & 2970.00 & 831.60 \\
\hline Rehabilitation & 2970.00 & 831.60 \\
\hline \multicolumn{3}{|l|}{ End-stage renal disease } \\
\hline Hemodialysis & 370.00 & 103.60 \\
\hline Kidney transplant & 1890.00 & 529.20 \\
\hline \multicolumn{3}{|l|}{ Blindness } \\
\hline Vitrectomy & 4305.00 & 1205.40 \\
\hline Hospitalization & 210.00 & 58.80 \\
\hline \multicolumn{3}{|l|}{ Diabetic foot syndrome } \\
\hline $\begin{array}{l}\text { Amputation of lower limb } \\
\text { and/or toes }\end{array}$ & 1354.50 & 379.26 \\
\hline $\begin{array}{l}\text { Prosthesis and two type II } \\
\text { outpatient visits }\end{array}$ & 865.52 & 242.35 \\
\hline \multicolumn{3}{|l|}{ Serious hypoglycemic event } \\
\hline Hospitalization & 1360.00 & 380.80 \\
\hline
\end{tabular}

Abbreviations: ACS, acute coronary syndrome; PLN, Polish złoty.

compared with manually coded blood glucose meters. The total cost of ACS status was determined to be PLN 15,715.65 $(€ 4400.38)$ and PLN 14,193.66 (€3974.23) from the perspective of the payer and the public payer, respectively. The cost of daily blood glucose monitoring from the perspective 
of the payer was PLN $0.96(€ 0.27)$ for CONTOUR ${ }^{\circledR}$ TS and PLN 1.04 (€0.29) for manually coded glucose meters. From the perspective of the public payer, the costs of daily glucose monitoring for CONTOUR ${ }^{\circledR}$ TS and manually coded blood glucose meters were both PLN 0.89 (€0.25). There was a significant $(P<0.005)$ cost benefit from the perspective of the public payer and a significant $(P<0.0001)$ cost benefit from the perspective of the payer derived from use of the CONTOUR ${ }^{\circledR}$ TS system versus manually coded blood glucose meters in diabetes management strategies (Table 2), which can most likely be attributed to the higher precision of the CONTOUR $^{\circledR}$ TS system. The incremental costs of comparison of CONTOUR ${ }^{\circledR}$ TS with manually coded blood glucose meters for the public payer and the payer are PLN 52.99 (€14.84) and PLN 187.13 (€52.40), respectively, per patient in the 26-year analysis horizon.

\section{Cost effectiveness and cost utility analyses}

When manually coded blood glucose meters are replaced by the CONTOUR ${ }^{\circledR}$ TS system in treatment schemes for patients with diabetes, the gain of an additional year of life is associated with a significant $(P<0.0001$ for both) savings from the perspective of the public payer (PLN 31,846.19 $[\mathrm{SD}=873.28] ; € 8916.93)$ and the payer (PLN 113,018.19 [SD = 8547.86]; $€ 31,645.09)$. Similarly, the gain of an additional quality-adjusted year of life is associated with a significant $(P<0.0001$ for both) savings for both the public payer (PLN 11,434.82 [SD = 433.92]; €3201.75) and the payer (PLN 40,465.59 [SD = 873.28]; €11,330.37) when the CONTOUR $^{\circledR}$ TS system is substituted for manually coded blood glucose meters. These results showed the cost utility and cost effectiveness of the CONTOUR ${ }^{\circledR}$ TS system for glucose monitoring from the perspectives of the payer and public payer, based on the threshold values assumed for cost utility (PLN 76,000 [€21,280]) per quality-adjusted life year gained) and cost effectiveness (PLN 58,000 [€16,240]) per life year gained).

\section{Sensitivity analyses}

Results of sensitivity analyses from the perspective of the public payer and the payer are presented in Tables 3 and 4. Sensitivity analyses evaluating the effects of age, control, $\mathrm{HbA}_{1 \mathrm{C}}$ reduction, and discount rate for costs and effects determined no changes to the conclusions of the primary analysis with respect to cost efficacy and cost utility as a result of these variables. Analysis of the effect of patient age on clinical efficacy (life years gained and quality-adjusted life years gained) indicated that the use of the CONTOUR ${ }^{\circledR}$ TS system may improve clinical outcomes for younger patients as compared with manually coded blood glucose meters. A significant effect on cost effectiveness and cost utility results was observed as a result of changing the value of the discount rate of costs and effects due to the long time horizon used in analysis; however, these effects did not change the overall conclusions of the primary analysis.

Sensitivity analyses were conducted to determine the threshold values at which the CONTOUR ${ }^{\circledR}$ TS system is superior to manually coded blood glucose in terms of cost to the public payer and the payer. Under the assumption that the cost of a package of test strips is limited by the retail price and the test strips are reimbursed 100\% from public funds, the diabetes management scheme involving the use of the CONTOUR ${ }^{\circledR}$ TS system in Poland results in savings to the public payer and the payer to a threshold gross wholesale price of PLN 42.47 (SD = 0.02; €11.89) and PLN 45.49 $(\mathrm{SD}=0.01 ; € 12.74)$, respectively, in the analysis horizon of 26 years. These values translate to threshold retail prices of PLN 49.27 (SD = 0.02; €13.80) and PLN 52.89 (SD = 0.01; $€ 14.81)$ for the public payer and the payer, respectively, indicating that even with an increase in the reimbursement limit for CONTOUR ${ }^{\circledR}$ TS test strips, the diabetes management

Table 2 Total cost of diabetes treatment per patient in the analysis horizon of 26 years from the perspective of the public payer (National Health Fund) and the payer (patient and National Health Fund)

\begin{tabular}{llll}
\hline & CONTOUR & Incremental cost \\
\hline Cost to public payer per patient discounted & & Manually coded meters & \\
to baseline state of analysis, mean (SD) & & & $-52.99(3.88)$ \\
$\quad$ PLN & $-I I, 25 I .36(5.16)$ & $-I I, 304.35(6.94)$ & $-14.84(I .09)$ \\
$\quad €$ & $-3 \mid 50.38(I .44)$ & $-3 \mid 65.22(I .94)$ & $-187.13(2.77)$ \\
Cost to payer per patient discounted to & & & $-52.40(0.78)$ \\
baseline state of analysis, mean (SD) PLN & & $-\mid 3,187.76(9.20)$ & $-3692.57(2.58)$ \\
$\quad$ PLN & $-\mid 3,000.63(7.69)$ & &
\end{tabular}

Abbreviations: SD, standard deviation; PLN, Polish złoty. 
Table 3 Incremental cost, life years gained, quality-adjusted life years gained, incremental cost-effectiveness ratio (cost efficacy), and incremental cost-utility ratio (cost utility) results from I- and 2-way sensitivity analyses for the payer (patient and National Health Fund)

\begin{tabular}{|c|c|c|c|c|c|c|c|c|}
\hline \multirow[t]{2}{*}{ Variable } & \multicolumn{2}{|c|}{$\begin{array}{l}\text { Incremental cost, } \\
\text { mean (SD) }\end{array}$} & \multirow[t]{2}{*}{ LYG } & \multirow[t]{2}{*}{ QALY } & \multicolumn{2}{|l|}{ ICER } & \multicolumn{2}{|c|}{ ICUR, mean (SD) } \\
\hline & $\overline{\mathbf{P L N}}$ & $€$ & & & $\overline{\text { PLN }}$ & $€$ & PLN & $€$ \\
\hline Age (43-53 years) & $\begin{array}{l}-229.28 \\
(3.38)\end{array}$ & $\begin{array}{l}-64.20 \\
(0.95)\end{array}$ & $\begin{array}{l}0.0027 \\
(0.0003)\end{array}$ & $\begin{array}{l}0.0068 \\
(0.0003)\end{array}$ & $\begin{array}{l}-87,123.93 \\
(7006.67)\end{array}$ & $\begin{array}{l}-24,394.70 \\
(1961.87)\end{array}$ & $\begin{array}{l}-34,006.7 \mid \\
(I I 52.43)\end{array}$ & $\begin{array}{l}-9,521.88 \\
(322.68)\end{array}$ \\
\hline Age (53-63 years) & $\begin{array}{l}-141.34 \\
(2.40)\end{array}$ & $\begin{array}{l}-39.58 \\
(0.67)\end{array}$ & $\begin{array}{l}0.0010 \\
(0.0001)\end{array}$ & $\begin{array}{l}0.0027 \\
(0.0001)\end{array}$ & $\begin{array}{l}-145,303.79 \\
(11,589.73)\end{array}$ & $\begin{array}{l}-40,685.06 \\
(3245.12)\end{array}$ & $\begin{array}{l}-52,137.85 \\
(1587.89)\end{array}$ & $\begin{array}{l}-14,598.60 \\
(444.6 I)\end{array}$ \\
\hline $\begin{array}{l}\text { Control } \\
\text { (ACCU-CHEK }{ }^{\circledR} \text { Active) }\end{array}$ & $\begin{array}{l}-179.86 \\
(2.94)\end{array}$ & $\begin{array}{l}-50.36 \\
(0.82)\end{array}$ & $\begin{array}{l}0.0016 \\
(0.0001)\end{array}$ & $\begin{array}{l}0.0046 \\
(0.0002)\end{array}$ & $\begin{array}{l}-|I I, 848.7| \\
(7977.39)\end{array}$ & $\begin{array}{l}-31,317.64 \\
(2233.67)\end{array}$ & $\begin{array}{l}-39,442.49 \\
(1085.55)\end{array}$ & $\begin{array}{l}-11,043.90 \\
(303.95)\end{array}$ \\
\hline $\begin{array}{l}\mathrm{HbA}_{\mathrm{IC}} \text { reduction } \\
(-0.17 \%)\end{array}$ & $\begin{array}{l}-189.72 \\
(2.48)\end{array}$ & $\begin{array}{l}-53.12 \\
(0.69)\end{array}$ & $\begin{array}{l}0.0010 \\
(0.0001)\end{array}$ & $\begin{array}{l}0.0038 \\
(0.0002)\end{array}$ & $\begin{array}{l}-186,061.99 \\
(22,041.12)\end{array}$ & $\begin{array}{l}-52,097.36 \\
(6 I 7 I .5 I)\end{array}$ & $\begin{array}{l}-50,166.38 \\
(1770.10)\end{array}$ & $\begin{array}{l}-14,046.59 \\
(495.63)\end{array}$ \\
\hline $\begin{array}{l}\text { Discount rate for costs } \\
\text { (from } 5 \% \text { to } 0 \% \text { ) }\end{array}$ & $\begin{array}{l}-289.74 \\
(4.08)\end{array}$ & $\begin{array}{l}-81.13 \\
(1.14)\end{array}$ & $\begin{array}{l}0.0017 \\
(0.0002)\end{array}$ & $\begin{array}{l}0.0046 \\
(0.0002)\end{array}$ & $\begin{array}{l}-175,388.87 \\
(12,808.73)\end{array}$ & $\begin{array}{l}-49,108.88 \\
(3586.44)\end{array}$ & $\begin{array}{l}-62,905.83 \\
(1998.97)\end{array}$ & $\begin{array}{l}-17,613.63 \\
(559.7 I)\end{array}$ \\
\hline $\begin{array}{l}\text { Discount rate for effects } \\
\text { (from } 5 \% \text { to } 0 \% \text { ) }\end{array}$ & $\begin{array}{l}-186.61 \\
(2.61)\end{array}$ & $\begin{array}{l}-52.25 \\
(0.73)\end{array}$ & $\begin{array}{l}0.0036 \\
(0.0003)\end{array}$ & $\begin{array}{l}0.0090 \\
(0.0004)\end{array}$ & $\begin{array}{l}-51,522.38 \\
(3338.54)\end{array}$ & $\begin{array}{l}-14,426.27 \\
(934.79)\end{array}$ & $\begin{array}{l}-20,739.50 \\
(563.5 I)\end{array}$ & $\begin{array}{l}-5807.06 \\
(157.78)\end{array}$ \\
\hline
\end{tabular}

Abbreviations: SD, standard deviation; PLN, Polish złoty; LYG, life years gained; QALY, quality-adjusted life years gained; ICER, incremental cost-effectiveness ratio; ICUR, incremental cost-utility ratio.

scheme involving CONTOUR ${ }^{\circledR}$ TS for blood glucose level measurement results in lower costs for both the public payer and the payer as compared with manually coded blood glucose meters with an analysis horizon of 26 years. In a similar evaluation comparing the CONTOUR ${ }^{\circledR}$ TS system with the ACCU-CHEK ${ }^{\circledR}$ Active glucose meter, assuming the cost of a package of test strips is limited by its retail price and is co-funded $100 \%$ from public funds, the threshold retail price of a package of strips is PLN 49.28 ( $\mathrm{SD}=0.04 ; € 13.80)$ and PLN $52.71(\mathrm{SD}=0.03 ; € 14.76)$ from the perspective of the public payer and the payer, respectively. Even with this increase in the reimbursement limit, diabetes management schemes involving the CONTOUR ${ }^{\circledR} \mathrm{TS}$ system are associated with reduced costs relative to the ACCU-CHEK ${ }^{\circledR}$ Active glucose meter. These sensitivity analyses showed no effect of the analyzed range of CONTOUR ${ }^{\circledR} \mathrm{TS}$ test strip prices on the findings with respect to cost savings for the CONTOUR ${ }^{\circledR}$ TS system from the primary analysis.

\section{Discussion}

Poor glycemic control results in reduced clinical outcomes for patients with diabetes and subsequent increases in medical costs related to the treatment of diabetic complications. Accurate blood glucose measurements are critical for the appropriate management of intensive blood glucose lowering therapy and the associated reduction in complications and

Table 4 Incremental cost, life years gained, quality-adjusted life years gained, incremental cost-effectiveness ratio (cost efficacy), and incremental cost-utility ratio (cost utility) results from I- and 2-way sensitivity analysis for the public payer (National Health Fund)

\begin{tabular}{|c|c|c|c|c|c|c|c|c|}
\hline \multirow[t]{2}{*}{ Variable } & \multicolumn{2}{|c|}{$\begin{array}{l}\text { Incremental cost, } \\
\text { mean (SD) } \\
\end{array}$} & \multirow[t]{2}{*}{ LYG } & \multirow[t]{2}{*}{ QALY } & \multicolumn{2}{|l|}{ ICER } & \multicolumn{2}{|l|}{ ICUR } \\
\hline & PLN & $€$ & & & PLN & $€$ & PLN & $€$ \\
\hline Age ( $43-53$ years) & $\begin{array}{l}-64.84 \\
(5.09)\end{array}$ & $\begin{array}{l}-18.16 \\
(1.43)\end{array}$ & $\begin{array}{l}0.0027 \\
(0.0003)\end{array}$ & $\begin{array}{l}0.0068 \\
(0.0003)\end{array}$ & $\begin{array}{l}-24,493.94 \\
(610.02)\end{array}$ & $\begin{array}{l}-6858.30 \\
(\mid 70.8 I)\end{array}$ & $\begin{array}{l}-9588.98 \\
(328.92)\end{array}$ & $\begin{array}{l}-2684.91 \\
(92.10)\end{array}$ \\
\hline Age (53-63 years) & $\begin{array}{l}-38.81 \\
(3.03)\end{array}$ & $\begin{array}{l}-10.87 \\
(0.85)\end{array}$ & $\begin{array}{l}0.0010 \\
(0.0001)\end{array}$ & $\begin{array}{l}0.0027 \\
(0.0001)\end{array}$ & $\begin{array}{l}-39,681.38 \\
(1,165.68)\end{array}$ & $\begin{array}{l}-11,110.79 \\
(326.39)\end{array}$ & $\begin{array}{l}-14,28 \mid .59 \\
(538.71)\end{array}$ & $\begin{array}{l}-3998.85 \\
(150.84)\end{array}$ \\
\hline $\begin{array}{l}\text { Control } \\
\text { (ACCU-CHEK }{ }^{\circledR} \text { Active) }\end{array}$ & $\begin{array}{l}-52.36 \\
(3.92)\end{array}$ & $\begin{array}{l}-14.66 \\
(1.10)\end{array}$ & $\begin{array}{l}0.0016 \\
(0.0001)\end{array}$ & $\begin{array}{l}0.0046 \\
(0.0002)\end{array}$ & $\begin{array}{l}-32,402.24 \\
(647.58)\end{array}$ & $\begin{array}{l}-9072.63 \\
(181.32)\end{array}$ & $\begin{array}{l}-11,456.80 \\
(432.73)\end{array}$ & $\begin{array}{l}-3207.90 \\
(121.16)\end{array}$ \\
\hline $\begin{array}{l}\mathrm{HbA}_{\mathrm{IC}} \text { reduction } \\
(-0.17 \%)\end{array}$ & $\begin{array}{l}-50.65 \\
(3.43)\end{array}$ & $\begin{array}{l}-14.18 \\
(0.96)\end{array}$ & $\begin{array}{l}0.0010 \\
(0.0001)\end{array}$ & $\begin{array}{l}0.0038 \\
(0.0002)\end{array}$ & $\begin{array}{l}-49,327.11 \\
(3,214.33)\end{array}$ & $\begin{array}{l}-13,811.59 \\
(900.01)\end{array}$ & $\begin{array}{l}-13,360.13 \\
(371.99)\end{array}$ & $\begin{array}{l}-3740.84 \\
(104.16)\end{array}$ \\
\hline $\begin{array}{l}\text { Discount rate for costs } \\
\text { (from } 5 \% \text { to } 0 \% \text { ) }\end{array}$ & $\begin{array}{l}-85.23 \\
(6.39)\end{array}$ & $\begin{array}{l}-23.86 \\
(1.79)\end{array}$ & $\begin{array}{l}0.0017 \\
(0.0002)\end{array}$ & $\begin{array}{l}0.0046 \\
(0.0002)\end{array}$ & $\begin{array}{l}-51,329.39 \\
(I 126.02)\end{array}$ & $\begin{array}{l}-14,372.23 \\
(315.29)\end{array}$ & $\begin{array}{l}-18,457.32 \\
(626.62)\end{array}$ & $\begin{array}{l}-5168.05 \\
(175.45)\end{array}$ \\
\hline $\begin{array}{l}\text { Discount rate for effects } \\
\text { (from } 5 \% \text { to } 0 \% \text { ) }\end{array}$ & $\begin{array}{l}-52.21 \\
(3.49)\end{array}$ & $\begin{array}{l}-14.62 \\
(0.98)\end{array}$ & $\begin{array}{l}0.0036 \\
(0.0003)\end{array}$ & $\begin{array}{l}0.0090 \\
(0.0004)\end{array}$ & $\begin{array}{l}-14,358.94 \\
(3 \mid 1.28)\end{array}$ & $\begin{array}{l}-4020.50 \\
(87.16)\end{array}$ & $\begin{array}{l}-5791.81 \\
(192.33)\end{array}$ & $\begin{array}{l}-|621.7| \\
(53.85)\end{array}$ \\
\hline
\end{tabular}

Abbreviations: SD, standard deviation; PLN, Polish złoty; LYG, life years gained; QALY, quality-adjusted life years gained; ICER, incremental cost-effectiveness ratio; ICUR, incremental cost-utility ratio. 
medical costs. The cost efficacy and utility analyses of the CONTOUR ${ }^{\circledR}$ TS system showed that a diabetes management scheme including use of the CONTOUR ${ }^{\circledR}$ TS system is superior to the use of manually coded blood glucose meters available in the Polish market from the perspective of the payer (patient and NHF) and the public payer (NHF). Clinical effectiveness analyses showed a small but significant gain of 0.0017 life years and 0.0046 quality-adjusted life years (equivalent to 0.6 days of life and 1.7 quality-adjusted days of life), in addition to a $0.09 \%$ improvement in $\mathrm{HbA}_{1 \mathrm{C}}$ levels, over the analysis horizon of 26 years with the replacement of manually coded glucose monitors used in Poland with the CONTOUR $^{\circledR}$ TS system. These effects may be more pronounced when the CONTOUR ${ }^{\circledR} \mathrm{TS}$ system is used in younger patients, as shown by the sensitivity analysis of age; although not evaluated in this study, there may be additional benefits for patients who have difficulty following manually coding procedures. The CONTOUR ${ }^{\circledR}$ TS system is also associated with a reduced risk of certain diabetic complications, including vision loss, serious hypoglycemic event, and amputation of the lower limb or toes due to diabetic foot syndrome, when compared with manually coded blood glucose meters.

The medical costs associated with the treatment of complications from diabetes are significantly greater than the costs of monitoring blood glucose levels. The higher precision of the CONTOUR ${ }^{\circledR}$ TS system is associated with lower costs of therapy related to diabetic complications compared with manually coded glucose meters. Additionally, results of this analysis showed a high cost effectiveness and cost utility for the CONTOUR ${ }^{\circledR}$ TS system relative to manually coded blood glucose meters. The economic benefits determined in this study for the CONTOUR ${ }^{\circledR}$ TS system may be more pronounced in clinical practice due to the additional benefits of the system, such as compensation for the effects of oxygen and maltose, which were not included in this analysis. Blood glucose measurements that correct for hematocrit levels are considered more reliable. Hematocrit is the percentage of erythrocytes in the blood and affects the reliability of blood glucose measurements. Higher hematocrit levels may cause glucose measurements to be lower than the actual values, and lower hematocrit levels may result in higher measurements than actual values. The CONTOUR ${ }^{\circledR}$ TS system corrects for hematocrit levels in a range of $0 \%-70 \%$, which is the widest range of corrected hematocrit values among blood glucose meters available in Poland.

The Monte Carlo method used in this analysis is considered highly reliable for evaluating the effects of a variable on the results of an analysis or on stability testing of results and conclusions of the primary analysis, and the large sample size used permitted the demonstration of high repeatability and statistical significance of the results. This method allowed patients with a wide range of blood glucose levels, from levels at the lower end of the diabetic range $(\sim 150 \mathrm{mg} / \mathrm{dL})$ to very high levels $(\sim 450 \mathrm{mg} / \mathrm{dL})$, to be considered in the analysis of the CONTOUR $^{\circledR}$ TS diagnostic scheme, thereby offering a more accurate reflection of the effects of glucose-lowering therapy in the treatment of patients with diabetes. The Markov model used for calculation of clinical effects and costs related to the analyzed diagnostic schemes offers a reliable representation of the outcomes for patients using either the CONTOUR ${ }^{\circledR}$ TS system or manually coded glucose meters.

One limitation of the model is disregarding certain states of patients who had diabetic complications (nephropathy, diabetic foot, etc), due to the lack of a correlation between $\mathrm{HbA}_{1 \mathrm{C}}$ level with the probability of transitions to these states. Addressing these issues in the future will elucidate the full benefit of the CONTOUR $^{\circledR}$ TS system over the ACCU-CHEK ${ }^{\circledR}$ Active System. An additional limitation was assigning patients in each of the analyzed groups a constant $\mathrm{HbA}_{1 \mathrm{C}}$ level throughout the 26-year analysis horizon. However, the clinical study ${ }^{23}$ by Wiener and Roberts showed that there was no correlation between patient age and $\mathrm{HbA}_{1 \mathrm{C}}$ levels. The reliability of the methods used in this analysis further strengthen the conclusion that use of the CONTOUR ${ }^{\circledR}$ TS system to replace manually coded blood glucose meters in diabetes management schemes is associated with a significant advantage with respect to cost utility and cost effectiveness from the perspectives of the payer and the public payer over a 26-year analysis horizon.

\section{Acknowledgments/disclosure}

This study was sponsored by Bayer Sp. z o.o. The sponsor provided financial support for conducting the analyses. Editorial assistance was provided by Megan Knagge, $\mathrm{PhD}$, of MedErgy and was funded by Bayer. Holko and Kawalec both contributed to the concept/design and data analysis/ interpretation, and the drafting, critical revision, and approval of this article.

\section{References}

1. Vinik AI, Vinik E. Prevention of the complications of diabetes. Am J Manag Care. 2003;9(3 Suppl):S63-S80.

2. International Diabetes Federation. Diabetes Atlas. Diabetes [homepage on the Internet]. Available from: http://www.diabetesatlas.org/content/ diabetes. Accessed November 23, 2010

3. Bragd J, Adamson U, Backlund LB, Lins PE, Moberg E, Oskarsson P. Can glycaemic variability, as calculated from blood glucose self-monitoring, predict the development of complications in type 1 diabetes over a decade? Diabetes Metab. 2008;34(6):612-616. 
4. The Diabetes Control and Complications Trial Research Group. The effect of intensive treatment of diabetes on the development and progression of long-term complications in insulin-dependent diabetes mellitus. N Engl J Med. 1993;329(14):977-986.

5. Kruger DF, Martin CL, Sadler CE. New insights into glucose regulation. Diabetes Educ. 2006;32(2):221-228.

6. Steffes MW. Glycemic control and the initiation and progression of the complications of diabetes mellitus. Kidney Int Suppl. 1997;63: S36-S39.

7. Menzin J, Langley-Hawthorne C, Friedman M, Boulanger L, Cavanaugh R. Potential short-term economic benefits of improved glycemic control: a managed care perspective. Diabetes Care. 2001; 24(1):51-55.

8. Wagner EH, Sandhu N, Newton KM, McCulloch DK, Ramsey SD, Grothaus LC. Effect of improved glycemic control on health care costs and utilization. JAMA. 2001;285(2):182-189.

9. Raine CH, Schrock LE, Edelman SV, et al. Significant insulin dose errors may occur if blood glucose results are obtained from miscoded meters. J Diabetes Sci Technol. 2007;1(2):205-210.

10. Kristensen GB, Nerhus K, Thue G, Sandberg S. Standardized evaluation of instruments for self-monitoring of blood glucose by patients and a technologist. Clin Chem. 2004;50(6):1068-1071.

11. Frank J, Rivera L, Wallace JF, Parkes JL. Performance and Ease of Use of the CONTOURTM TM TS Blood Glucose Monitoring System: Capillary, Venous and Alternative Site Testing (AST) Blood. Tarrytown, NY: Bayer HealthCare Diabetes Care; 2007.

12. Tufts Medical Center, Institute for Clinical Research and Health Policy Studies. The Cost Effectiveness Analysis Registry Database, Center for the Evaluation of Value and Risk in Health (CEVR) [homepage on the Internet]. Available from: https://research.tufts-nemc.org/cear/. Accessed December 3, 2008.

13. Ministerstwo Zdrowia. Internet portal of the Ministry of Health [homepage on the Internet]. Available from: http://www.mz.gov.pl/. Accessed November 11, 2008.
14. Medycyna Praktyczna Portal [homepage on the Internet]. Available from: http://www.mp.pl. Accessed November 11, 2008.

15. Health Technology Assessment Agency website [homepage on the Internet]. Available from: http://www.aotm.gov.pl/. Accessed November 11, 2008.

16. Central Statistical Office of Poland. National Census of People and Dwellings 2011 [homepage on the Internet]. Available from: http:// www.stat.gov.pl./gus/index_ENG_HTML.htm. Accessed November 23, 2010

17. Goldstein DE, Little RR, Lorenz RA, et al. Tests of glycemia in diabetes. Diabetes Care. 2004;27(7):1761-1773.

18. Farmer A, Wade A, Goyder E, et al. Impact of self monitoring of blood glucose in the management of patients with non-insulin treated diabetes: open parallel group randomised trial. BMJ. 2007;335(7611):132.

19. Palmer AJ, Roze S, Valentine WJ, et al. The CORE Diabetes Model: Projecting long-term clinical outcomes, costs and cost-effectiveness of interventions in diabetes mellitus (types 1 and 2) to support clinical and reimbursement decision-making. Curr Med Res Opin. 2004;20 Suppl 1: S5-S26.

20. Stratton IM, Adler AI, Neil HAW, et al. Association of glycaemia with macrovascular and microvascular complications of type 2 diabetes (UKPDS 35): prospective observational study. BMJ. 2000; 321(7258):405-412.

21. Molyneaux LM, Constantino MI, McGill M, Zilkens R, Yue DK. Better glycaemic control and risk reduction of diabetic complications in Type 2 diabetes: comparison with the DCCT. Diabetes Res Clin Pract. 1998; 42(2):77-83.

22. Kumala-Szczeklik Z, Tatón J. Wplyw cukrzycy na wsaka Ÿniki chorobowoœci I œmiertelnoœcu w powodu ostrego zawalu serca. Medycyna Metaboliczna. 1999;92:169-173.

23. Wiener K, Roberts NB. Age does not influence levels of HbA1c in normal subject. QJM. 1999;92(3):169-173.

\section{Publish your work in this journal}

Diabetes, Metabolic Syndrome and Obesity: Targets and Therapy is an international, peer-reviewed open-access journal committed to the rapid publication of the latest laboratory and clinical findings in the fields of diabetes, metabolic syndrome and obesity research. Original research, review, case reports, hypothesis formation, expert opinion and commentaries are all considered for publication. The manuscript management system is completely online and includes a very quick and fair peer-review system, which is all easy to use. Visit http://www.dovepress.com/testimonials.php to read real quotes from published authors. 